\title{
Analysis of FRP-Strengthened RC Members with Varied Sheet Bond Stress-Slip Models
}

\author{
HuneBum $\mathrm{Ko}^{1}$ and Yuichi Sato ${ }^{2}$
}

Received 29 January 2004, accepted 30 May 2004

\begin{abstract}
Finite element analysis was conducted for ten RC specimens, which were shear-strengthened with fiber-reinforced polymer (FRP) sheets. Four of the ten specimens were wrapped with unbonded sheets to observe influence of the bond to the strengthening effectiveness. The tests and analyses demonstrated that the unbonded sheets are not effective to increase the shear strength of a member without steel stirrups while the flexural ductility of a member can be improved by confinement with unbonded sheets. Parametric calculations were attempted with varied interfacial fracture energy $G_{f}$ and maximum bond stress $\tau_{y}$ between the sheet and concrete. The calculations indicated that the $G_{f}$ and the $\tau_{y}$ have limited influence on the shear strength while the local stresses and crack widths can be controlled to a certain extent.
\end{abstract}

\section{Introduction}

Fiber-reinforced polymer (FRP) sheets transversely jacketed around RC members enhance shear strength and flexural ductility (JCI 1998 and JCI 2003). In parallel to researches on structural performance of members, local bond behavior between the sheet and concrete has been investigated with great efforts since the bond is considered as an important factor for the strengthening effectiveness. The JCI Technical Committee on Retrofitting Technology for Concrete Structures issued a state of the art report in 2003 (JCI 2003). About half of this report discusses the bond behavior between the strengthening material and the concrete.

Flexural strengthening is another major usage of FRP sheets, where the sheets are longitudinally applied along members. Flexural strengthening requires tension development of the sheet, and importance of the bond is widely recognized. On the other hand, no unified agreement has been made on contribution of the bond to shear strengthening. For this reason, a working group of the Technical Committee conducted analyses of benchmark specimens and discussed on the bond characteristics and strengthening effectiveness.

The benchmark specimens consisted of five beams and ten columns strengthened with carbon or aramid fiber sheets (Asakura 1994, Ishizaki 1997 and Fukuyama 1998). Six of the specimens were wrapped with-

\footnotetext{
${ }^{1}$ Assistant Professor, Department of Architecture, Inha Technical College, Incheon, Korea (Visiting researcher in Kyoto Univ., Kyoto, Japan).

E-mail: hbko@inhatc.ac.kr

${ }^{2}$ Research Associate, Department of Urban and Environmental Engineering, Kyoto University, Kyoto, Japan.

E-mail: satou@archi.kyoto-u.ac.jp
}

out providing bond to the concrete. The analyses were conducted by three different kinds of method: (1) a method based on Modified Compression Field Theory (Vecchio 1986), (2) a model, which consists of two rigid bodies separated by a diagonal shear crack, and (3) finite element method. Based on this analytical research a parametric study has been conducted, varying fracture energy $G_{f}$ of the bonding interface. The report finally pointed out the following remarks:

(a) Increase of shear crack width causes significant increase of FRP sheet strain when the sheet is bonded.

(b) Relatively small sheet strain was observed when the sheet is wrapped without bonding.

(c) Shear strength increment depends on shear-reinforcing steel bar content, and sheet stiffness.

(d) The bond characteristics have limited influence on the ductility of strengthened member.

This paper selects ten specimens from the benchmark specimens and presents FE analysis results to make detailed discussions on the influence of the sheet bond. The analysis adopts an improved model for post-peak response of concrete. The calculations were conducted with varied bond stress-slip relations. Relationships between the bond, shear strength, ductility, sheet strains, and crack widths are discussed based on the analysis.

\section{Analyzed specimens}

Table 1 and Fig. 1 summarize the configurations of the selected ten specimens, five RC beams made by Ishizaki et al. (Ishizaki 1997) and five RC columns by Fukuyama et al. (Fukuyama 1998). Four of these specimens possessed bond between the sheet and concrete while the other four were wrapped with unbonded sheets. Two control specimens without sheet wrapping were also scheduled. Ishizaki reported that unbonded sheets re- 
sulted in an inferior shear capacity increment for a beam with no shear-reinforcing steel bars, while slight difference was observed in effectiveness of ductility enhancement between bonded and unbonded sheets in Fukuyama's study.

The FE program used for the analysis is VecTor2 developed by Vecchio (Vecchio 2000). Fig. 1 illustrates mesh dividing of models for the specimens. The models adopt four-node plane-stress rectangular elements to represent concrete with smeared reinforcement (=stirrup or hoop). Longitudinal steel bars and FRP sheet are modeled by two-node truss elements, and bond of steel and FRP by four-node joint elements (contact elements). Degree of freedom of the model was 1,387 for Ishizaki's specimens and 2,292 for Fukuyama's. Total number of elements was 868 for Ishizaki's and 1498 for Fukuyama's (Table 2).

\section{Bond stress-slip relationship}

Figure 2 shows typical bond stress-slip relations between FRP sheet and concrete obtained from tests by the authors, based on the JCI's specification (JCI 1998). The analyses in this paper adopted a bilinear assumption, which is defined by maximum bond stress $\tau_{y}$ and two characteristic slips $S_{y}$ and $S_{u}$. In a cyclic loading condition, linear unloading and reloading paths, which intersect the origin, were assumed. The area enveloped by the curve is defined as interfacial fracture energy $G_{f}$. Previous researches have indicated that the $G_{f}$ varied from $0.3 \mathrm{~N} / \mathrm{mm}$ up to $1.5 \mathrm{~N} / \mathrm{mm}$ (JCI 1998 and JCI 2003). Sato proposed maximum bond stress $\tau_{y}$ as a function of $G_{f}$ by Eq.(1) (Sato 2003a).

$$
\tau_{y}=6.6 \sqrt{G_{f}}
$$

Table 1 Configurations of analyzed specimens.

\begin{tabular}{|c|c|c|c|c|c|c|c|c|c|c|}
\hline Specimen & $\begin{array}{l}f^{\prime \prime}{ }_{c} \\
\mathrm{MPa}\end{array}$ & $\begin{array}{c}\mathrm{M} \\
/ \mathrm{VD} \\
\end{array}$ & $\begin{array}{l}\text { Longitudinal } \\
\text { reinforcement }\end{array}$ & $\begin{array}{l}\text { Lateral } \\
\text { reinforcement }\end{array}$ & $\begin{array}{c}\rho_{F} \\
\% \\
\end{array}$ & $\begin{array}{c}t_{F} \\
\mathrm{~mm}\end{array}$ & $\begin{array}{c}E_{F} \\
\mathrm{GPa}\end{array}$ & $\begin{array}{l}f_{F u}{ }^{* 1} \\
\mathrm{MPa}\end{array}$ & Bond $^{* 2}$ & $\begin{array}{l}V_{\text {exp }} \\
\mathrm{kN} \\
\end{array}$ \\
\hline No.1 & \multirow{5}{*}{32.6} & \multirow{5}{*}{1.9} & \multirow{5}{*}{$\begin{array}{c}\rho_{t}=1.82 \% \\
f_{t y}=350 \mathrm{MPa} \\
d_{b t}=38 \mathrm{~mm}\end{array}$} & \multirow{5}{*}{$\begin{array}{l}\rho_{w}=0.0 \% \\
f_{t w}=-- \\
d_{b w}=--\end{array}$} & 0.0 & -- & -- & -- & -- & 181 \\
\hline No. 2 & & & & & 0.036 & 0.11 & 244 & 2900 & $\mathrm{~B}$ & 285 \\
\hline No.3 & & & & & 0.054 & 0.17 & 80 & 2400 & B & 236 \\
\hline No.4 & & & & & 0.036 & 0.11 & 244 & 2900 & $\mathrm{U}$ & 184 \\
\hline No. 5 & & & & & 0.054 & 0.17 & 80 & 2400 & $\mathrm{U}$ & 177 \\
\hline S-RC-0 & 33.9 & \multirow{5}{*}{1.5} & \multirow{5}{*}{$\begin{array}{c}\rho_{t}=0.56 \% \\
f_{t y}=792 \mathrm{MPa} \\
d_{b t}=13 \mathrm{~mm}\end{array}$} & \multirow{5}{*}{$\begin{array}{c}\rho_{w}=0.13 \% \\
f_{t w}=360 \mathrm{MPa} \\
d_{b w}=6 \mathrm{~mm}\end{array}$} & 0.0 & -- & -- & -- & -- & 236 \\
\hline S-RC-B & 29.6 & & & & 0.074 & 0.11 & 236 & 4490 & $\mathrm{~B}$ & 288 \\
\hline S-RC-N & 35.0 & & & & 0.074 & 0.11 & 236 & 4490 & $\mathrm{U}$ & 270 \\
\hline S-M12-B & 34.8 & & & & 0.074 & 0.11 & 236 & 4490 & $\mathrm{~B}$ & 338 \\
\hline S-M12-BP & 35.3 & & & & 0.074 & 0.11 & 236 & 4490 & $\mathrm{U}$ & 340 \\
\hline
\end{tabular}

$* 1: f_{F u}=$ rupture stress of sheet. $* 2: \mathrm{B}=$ bonded, $\mathrm{U}=$ unbonded.

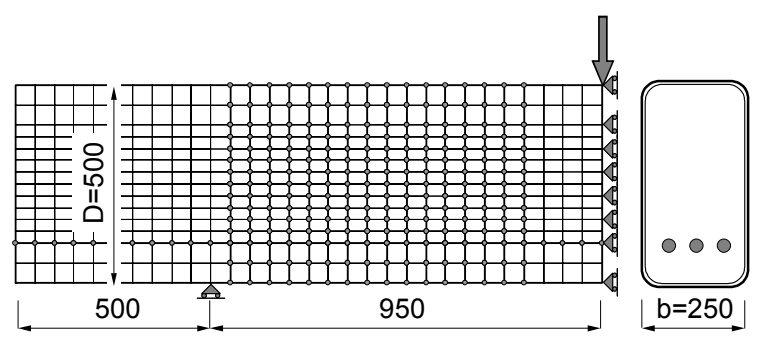

(a) Ishizaki (1997)

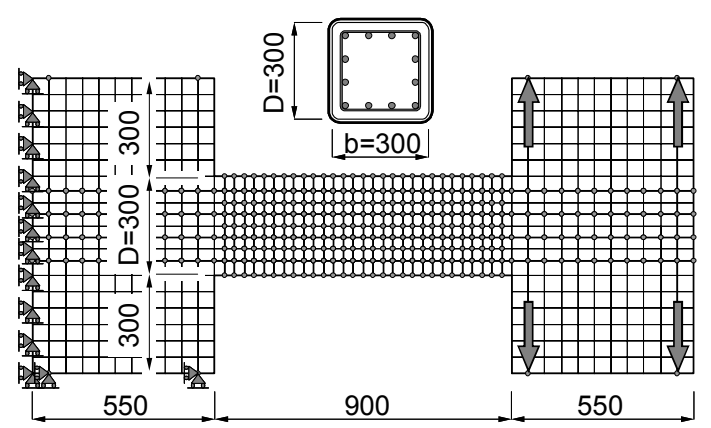

(b) Fukuyama (1998)

Fig.1 Geometry and mesh dividing of specimens.

Table 2 Analysis models.

\begin{tabular}{|c|c|c|c|}
\hline \multicolumn{2}{|c|}{ Literature } & Ishizaki & Fukuyama \\
\hline \multicolumn{2}{|c|}{ Degree of freedom } & 1,387 & 2,292 \\
\hline \multirow{4}{*}{$\begin{array}{c}\text { Number of } \\
\text { elements }\end{array}$} & Rectangular & 420 & 680 \\
\cline { 2 - 4 } & Truss (steel) & 30 & 212 \\
\cline { 2 - 4 } & Truss (FRP) & 224 & 232 \\
\cline { 2 - 4 } & Contact (steel) & 28 & 200 \\
\cline { 2 - 4 } & Contact (FRP) & 192 & 174 \\
\cline { 2 - 4 } & Total & 868 & 1,498 \\
\hline \multicolumn{2}{|c|}{ Total steps } & 40 & 568 \\
\hline \multicolumn{2}{|c|}{ Prescribed disp. increment } & $0.5 \mathrm{~mm}$ & $1.0 \mathrm{~mm}$ \\
\hline
\end{tabular}
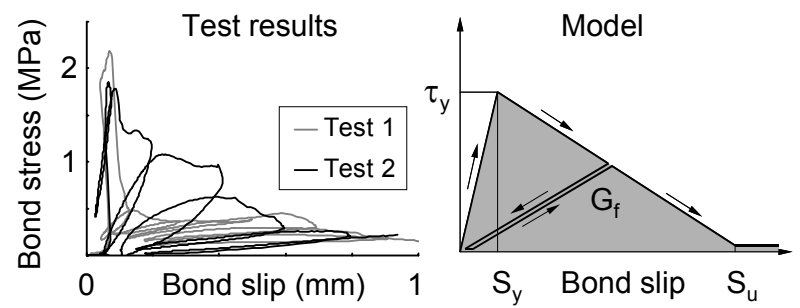

Fig.2 Bond stress-slip relationship between FRP sheet and concrete. 
Characteristic bond slips $S_{y}$ and $S_{u}$ are given by Eqs.(2) and (3).

$$
\begin{aligned}
& S_{y}=0.057 \sqrt{G_{f}} \\
& S_{u}=2 G_{f} / \tau_{y}
\end{aligned}
$$

The units of $\tau_{y}, G_{f}, S_{y}$ and $S_{u}$ are $\mathrm{MPa}$ and $\mathrm{N} / \mathrm{mm}$, $\mathrm{mm}$ and $\mathrm{mm}$.

\section{Crack spacing model}

Sato and Vecchio made a model equation to estimate crack spacing of RC with FRP sheet wrapping based on calculations of equilibrium and compatibility conditions between reinforcement and concrete (Sato 2003a). Equations (4) to (6) give crack spacing $s_{\mathrm{r}}$ based on this model.

$$
\begin{aligned}
& S_{r}=\frac{f_{t}{ }^{\prime}}{2 \sum_{i=1}^{m} \frac{\rho_{e, i} \tau_{b 0, i} \cos \theta_{s, i}}{d_{b, i}}+\frac{1}{220} \sum_{j=1}^{n} \frac{\rho_{F, j} c_{3, j} \cos ^{2} \theta_{F, j}}{t_{F, j}}} \\
& \left(s_{r} \leq 220 \mathrm{~mm}\right) \\
& S_{r}=\frac{f_{t}^{\prime}-\sum_{j=1}^{m} \frac{\rho_{F, j} c_{3, j} \cos ^{2} \theta_{F, j}}{t_{F, j}}}{2 \sum_{i=1}^{n} \frac{\rho_{e, i} \tau_{b 0, i} \cos \theta_{s, i}}{d_{b, i}}} \\
& \left(s_{r}>220 \mathrm{~mm}\right)
\end{aligned}
$$

where

$c_{3}=\left(15.8+1.34 \sqrt{t_{F} E_{F}}\right) \sqrt{G_{f}}$

$(\mathrm{N} / \mathrm{mm})$

$f^{\prime}{ }_{t}=$ tensile strength of concrete $(\mathrm{MPa})$;

$\rho_{e}=$ reinforcement ratio of steel bar;

$\tau_{b 0}=$ average bond stress along steel bar $(\mathrm{MPa})=2 f^{\prime}{ }_{t}$;

$\theta_{s}=$ angle between steel bar and direction of principal tensile concrete stress;

$d_{b}=$ steel bar diameter $(\mathrm{mm})$;

$\rho_{F}=$ reinforcement ratio of FRP sheet;

$\theta_{F}=$ angle between FRP sheet and direction of principal tensile concrete stress;

$t_{F}=$ thickness of FRP sheet (mm);

$E_{F}=$ elastic modulus of FRP sheet (MPa); and

$G_{f}=$ area enveloped by bond stress-slip curve $(\mathrm{N} / \mathrm{mm})$.

\section{Strength and post-peak response of confined concrete}

Confinement of the concrete by transverse stresses enhances the strength and ductility of the concrete, transforming the failure in compression from brittle to ductile. Although the finite element algorithm used in this paper was formulated for the plane stress state, the pro- gram accounts for out-of-plane stresses due to confinement of lateral expansion by out-of-plane reinforcement. The triaxial stress state is then utilized in computing the strength enhancement effects due to confinement (Vecchio 1992).

Figure 3 presents compressive stress-strain relations of concrete obtained from cyclic tests of five column specimens (Sato 2003b and Sato 2003c). The relations represent stress-strain hysteretic response of plastic hinge region, which were heavily confined with steels and FRP sheets. The specimens were $400 \mathrm{~mm}$ by 400 $\mathrm{mm}$ in cross-section and $1,200 \mathrm{~mm}$ in clear span $(M / V D$ $=1.5)$. The flexural reinforcement ratio $\rho_{t}$ was $0.90 \%$ for Specimen K1 to K4, and $1.08 \%$ for H6C. Applied axial force ratio was $N /\left(b D f^{\prime}{ }_{c}\right)=0.15$.

The concrete stresses and strains were derived from sixty-five displacement transducers and approximately one hundred strain gages applied on steels and FRP sheets. The confinement resulted in significant enhancement of ductility. In Specimen K2, a large tensile strain was observed under compression because of dilatation of concrete.

In the model of Park, Priestly and Gill (Park 1982), the residual compressive stress $f_{p r}$ is given as $0.2\left(1+\rho_{w}\right.$ $\left.f_{w y}\right) f_{c}$. The residual stresses observed in the five specimens, however, were considerably larger than those given by $0.2\left(1+\rho_{w} f_{w y}\right) f_{c}^{\prime}$. Hence, the authors attempt to modify the Park's formulation based on curve fitting with the experimental results:

$$
\begin{aligned}
f_{c 2}=-\beta_{1}\left|f_{c}{ }_{c}\right|\left\{1+Z_{m}\left(\varepsilon_{c 2}-\beta_{1} \varepsilon_{0}\right)\right\} & <f_{p r} \\
& \text { for } \varepsilon_{c 2}<\varepsilon_{p}<0
\end{aligned}
$$

where

$f_{c 2}=$ principal compressive concrete stress;

$\varepsilon_{c 2}=$ principal concrete strain;

$$
\begin{gathered}
Z_{m}=\frac{0.5}{\frac{3+0.29\left|f^{\prime}{ }_{c}\right|}{145\left|f^{\prime}{ }_{c}\right|-1000} \cdot\left(\frac{\beta_{1} \varepsilon_{0}}{-0.002}\right)+0.75 \rho_{w} \sqrt{\frac{b_{e}}{s_{w}}}} \\
f_{p r}=-\left(4800 \rho_{w}\right)^{0.8}\left(f_{w y} / 360\right)^{0.55}-4.1 \rho_{F} E_{F} \varepsilon_{F e} \\
<-0.3\left|f_{c}{ }_{c}\right|
\end{gathered}
$$

$b_{e}=$ effective width of member (mm);

$E_{F}=$ elastic modulus of FRP sheet (MPa);

$s_{w}=$ spacing of hoop or tie (mm);

$f_{w y}=$ yield stress of hoop or tie (MPa);

$\beta_{1}=$ strength enhancement factor of confined concrete;

$\varepsilon_{0}=$ strain at peak stress of unconfined concrete;

$\varepsilon_{\mathrm{Fe}}=$ effective confining strain of FRP sheet;

$\rho_{F}=$ reinforcement ratio of FRP sheet; and

$\rho_{w}=$ reinforcement ratio of stirrup, hoop or tie. 


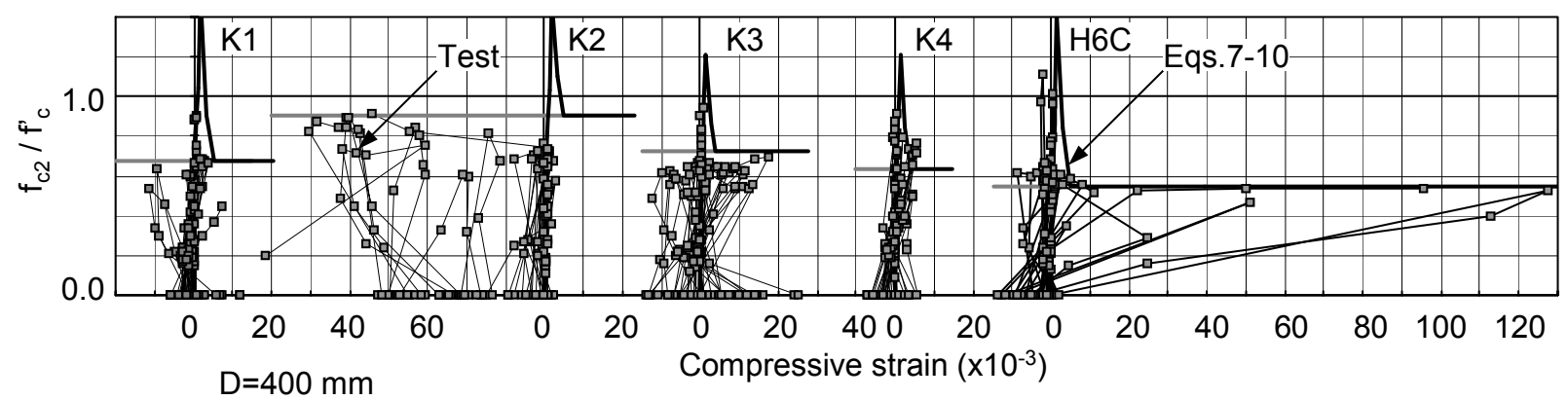

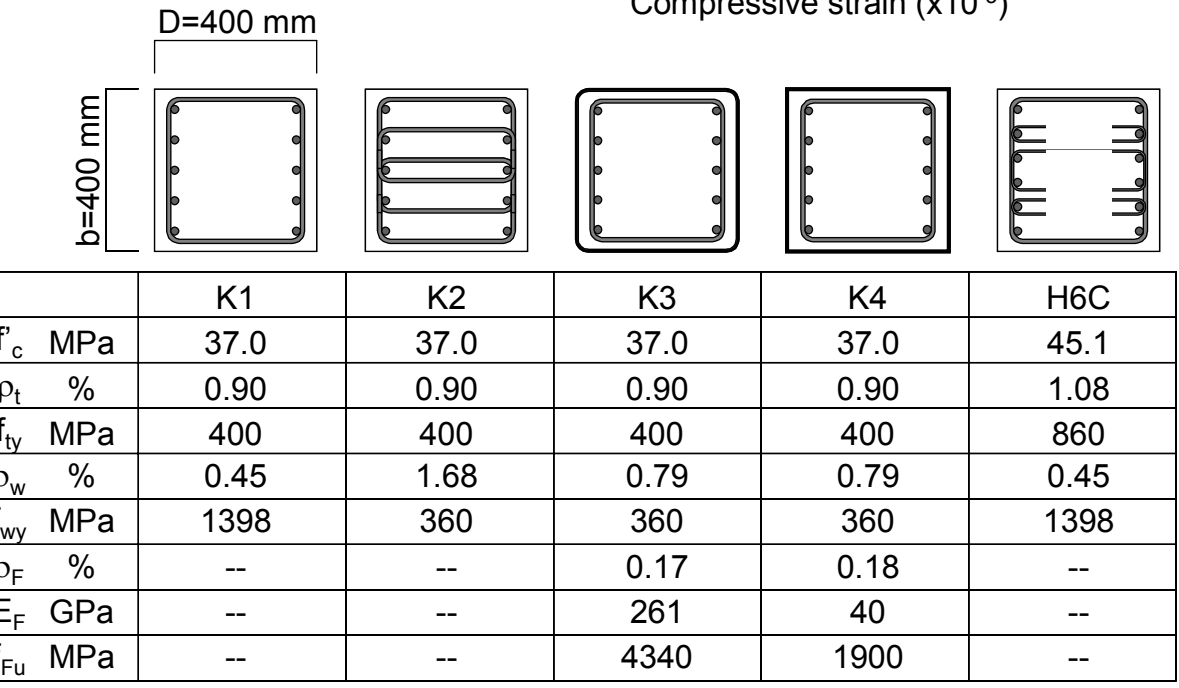

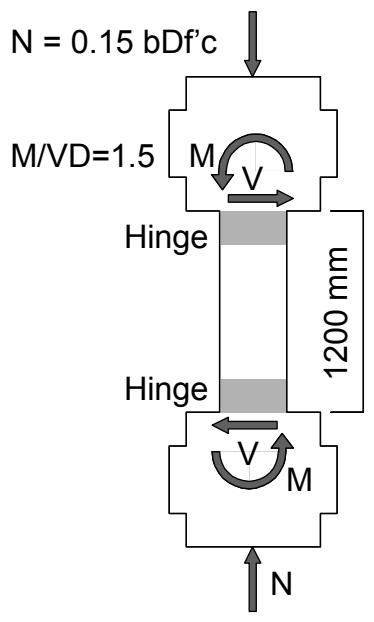

Fig.3 Compressive stress-strain relationships of concrete in plastic hinge.

Equation (9) gives the residual compressive stress $f_{p r}$ of concrete. Several previous researches, including Park's work, have defined the residual compressive stress as linear function of $\rho_{w} f_{w y}$ term. This assumption, however, overestimates ductility of columns confined with ultra high strength steel bars.

For this reason, the first term of Eq.(9) defines the contribution of steel confinement with through the variables of $\rho_{w}$ and $f_{w y}$. The second term gives the contribution of the FRP sheet. The coefficient 4.1 is adopted in accordance with work of Richart et al. (Richart 1928). Previous tests by the authors showed that the FRP sheets wrapped around hinge regions of shear-flexural members rarely ruptured although those wrapped around columns under uniaxial compression always did (Sato 2003b). Hence, the confining action of FRP sheet for shear-flexural members is given by effective strain $\varepsilon_{F e}$. Figure 4 shows FRP sheet strain at maximum shear force of shear critical beams and columns with respect to stiffness of the sheet $\rho_{F} E_{F}$ (Sato 1999). The data shown in Fig. 4 represents in-plane strains whereas the $\varepsilon_{F e}$ in Eq.(9) is out-of-plane strain. The out-of-plane strain, however, is usually lower than the in-plane strain when the member is subjected to an in-plane shear-flexural load. In other words, the strains in Fig. 4 can be viewed as an upper limit of the out-of-plane strains. For this reason, the effective sheet strain in out-of-plane direction is given by Equation (10):

$$
\varepsilon_{F e}=-0.001-0.007 \ln \left(\rho_{F} E_{F} / 1000\right)
$$

A curve given by Eq.(10) is drawn in Fig. 4. Note that Eq.(10) is only available for in-plane shear-flexural condition, but not for uniaxial compression nor biaxial shear-flexural condition.

The strength enhancement factor $\beta_{1}$ for the direction of the largest compressive stress, $f_{c 3}$, is determined by the equation below according to researches of Richart et al. and Kupfer et al. (Kupfer 1969).

$$
\begin{array}{r}
\beta_{1}=\left[1+0.92\left(\frac{f_{c n}}{f_{c}^{\prime}}\right)-0.76\left(\frac{f_{c n}}{f_{c}^{\prime}}\right)^{2}\right]+ \\
\left(f_{c 3}<f_{c 2}<f_{c 1}<0\right)
\end{array}
$$

where

$$
f_{c n}=-\left(f_{c 2}-f_{c 1}\right)>0
$$

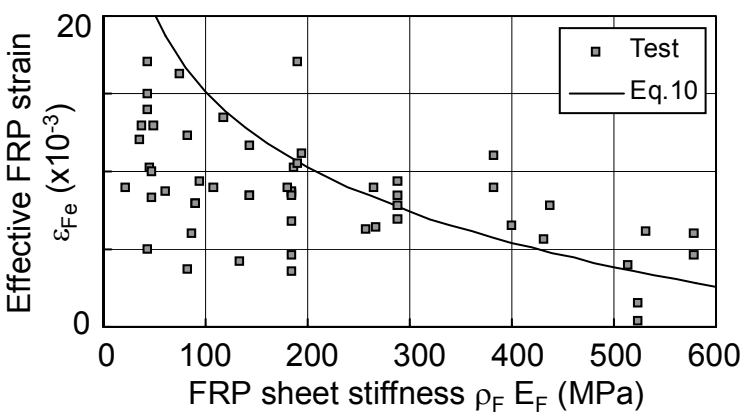

Fig.4 Effective strain of FRP sheet (Sato 1999). 


$$
f_{c 1}=-f_{c 1}<0
$$

Contribution of the FRP sheet to the enhancement factor $\beta_{1}$ is neglected because the confining force provided by the sheet at peak stress of the concrete is negligibly small. Equations (7) to (13) were incorporated with a hysteretic response formulation developed by Palermo (Palermo 2003).

\section{Crack width limit}

Vecchio pointed out that formation of a dominant shear crack of a lightly reinforced RC member is localized in a narrow band (Vecchio 2000). In finite element analysis, it is reasonable to discount the ability to sustain compressive stresses in elements located along the dominant crack. Vecchio proposed to reduce the principal compressive stress when the computed crack width exceeds $2 \mathrm{~mm}$.

The authors modified this model in three aspects. Firstly, the crack width limit is usually needless in RC elements with heavy reinforcement contents. Typical instance is a plastic hinge with heavy confinement, which sustains under large compression regardless of a number of widely opened cracks contained. A threshold is therefore introduced to decide whether a finite element needs the crack width limit check. The analyses conducted in this paper checks the width only in elements, which satisfy a condition given by Eq.(14):

$$
\Sigma\left(\rho_{s i} \cos \theta_{s i} / d_{b i}\right)<0.00075
$$

where

$$
\begin{aligned}
\rho_{s i}= & \text { reinforcement ratio of } i \text {-th component of steel } \\
& \text { bar; } \\
\theta_{s i}= & \text { angle between orientation of } i \text {-th bar component } \\
& \text { and direction of principal tensile concrete stress; } \\
& \text { and } \\
d_{b i}= & \text { bar diameter of } i \text {-th component. }
\end{aligned}
$$

Secondly, it is found that wrapping a RC member with carbon fiber sheets provides considerably improved strength and ductility. On the other hand, those with low-modulus sheets (e.g. aramid or glass fibers) resulted in inferior strengthening effectiveness. Elastic modulus of carbon fiber ranges from $200 \mathrm{GPa}$ up to 400 $\mathrm{GPa}$ while those of aramid fiber and glass fiber are lower than $100 \mathrm{GPa}$. It is therefore proposed to omit the crack width limit for specimens wrapped by FRP sheets with an elastic modulus of $100 \mathrm{GPa}$ or higher.

Thirdly, the critical crack width was reduced by $1 \mathrm{~mm}$ based on extended analytical studies of lightly reinforced RC elements.

\section{Variation of bond characteristics}

Five cases of calculation were performed for the speci-
Table 3 Bond stress-slip relation model.

\begin{tabular}{|c|l|c|c|c|c|c|}
\hline \multicolumn{2}{|c|}{ Case } & 1 & 2 & 3 & 4 & 5 \\
\hline$G_{f}$ & $\mathrm{~N} / \mathrm{mm}$ & 0.3 & 0.9 & 0.9 & 0.9 & 1.5 \\
\hline$\tau_{y}$ & $\mathrm{MPa}$ & 3.61 & 1.565 & 6.26 & 25.05 & 8.08 \\
\hline$S_{y}$ & $\mathrm{~mm}$ & 0.031 & 0.054 & 0.054 & 0.054 & 0.070 \\
\hline$S_{u}$ & $\mathrm{~mm}$ & 0.166 & 1.15 & 0.287 & 0.072 & 0.371 \\
\hline
\end{tabular}

Table 4 Constitutive models and analysis conditions.

\begin{tabular}{|l|l|}
\hline Compression Base Curve: & Parabola \\
\hline Compression Post-Peak: & Eqs.(6)-(10) \\
\hline Compression Softening: & Vecchio 1992 \\
\hline Tension Stiffening: & Sato 2003a \\
\hline Crack spacing: & Eqs.(4)-(6) \\
\hline Tension Softening: & $\begin{array}{l}\text { Linear } \\
\left(G_{f}=0.075 \mathrm{~N} / \mathrm{mm}\right)\end{array}$ \\
\hline Confinement Strength: & Eqs.(11)-(13) \\
\hline Concrete Dilatation: & Kupfer 1969 \\
\hline Cracking Criterion: & Mohr-Coulomb \\
\hline Crack Width Check: & Eq.(14) \\
\hline Steel Bond & Fujii 1981 \\
\hline Concrete Hysteresis: & Palermo 2003 \\
\hline Steel Hysteresis: & Seckin 1981 \\
\hline Rebar Dowel Action: & He 2001 \\
\hline Slip Distortion: & Walraven 1981 \\
\hline
\end{tabular}

mens bonded with sheets to observe influence of the bond stress-slip curves (Table 3). Firstly, fracture energy $G_{f}$ was varied by $0.3 \mathrm{~N} / \mathrm{mm}, 0.9 \mathrm{~N} / \mathrm{mm}$, and 1.5 $\mathrm{N} / \mathrm{mm}$ (Case 1, 3, and 5). In these cases, the characteristic bond stress $\tau_{y}$ and the slip $S_{y}$ were determined by Eqs.(1) and (2). Secondly, the $\tau_{y}$ was varied by 0.25 times the value given by Eq.(1) (Case 2) and four times (Case 4), maintaining the $G_{f}$ constant at $0.9 \mathrm{~N} / \mathrm{mm}$. Table 3 summarizes the variation of $G_{f}, \tau_{y}$, and $S_{y}$. Table 4 presents other material models adopted in the analysis.

\section{Analysis results}

Table 5 shows analysis results of Ishizaki's specimens. The bond characteristics $\left(G_{f}\right.$ and $\left.\tau_{y}\right)$ were varied for Specimens No.2 and No.3. The calculated shear strengths of Specimens No.2 and No.3 were slightly varied by the difference of $G_{f}$ and $\tau_{y}$. The calculated average sheet strains ranged from $1.36 \times 10^{-3}$ up to 2.24 $\times 10^{-3}$ at maximum load for specimens with carbon fiber (No.2 and No.4) while $0.49 \times 10^{-3}$ up to $0.94 \times 10^{-3}$ for specimens with aramid fiber (No.3 and No.5). Figure 5 compares shear force-deflection relations between test and analysis. " $\left(G_{f}\right)$ " indicates comparison between Cases 1, 3, and 5 while " $\left(\tau_{y}\right)$ " applies Cases 2, 3, and 4.

Figure 6 presents crack patterns, FRP strains, and bond stresses of Specimen No.2 at maximum shear load. Difference was observed in the analysis results between the five cases. The analysis of Fukuyama's specimens was conducted with total 568 calculation steps, which follows hysteretic rule adopted in the test. Thickness of Specimens S-M12-B and S-M12-BP were assumed to be $340 \mathrm{~mm}$ (300 $\mathrm{mm}$ for other specimens) in order to 
Table 5 Analysis results (Ishizaki 1997).

\begin{tabular}{|c|c|c|c|c|c|c|c|c|c|c|c|c|c|}
\hline Specimen & No.1 & \multicolumn{9}{|c|}{ No.2 } & \multicolumn{7}{c|}{ No.3 } & No.4 & No.5 \\
\hline Case & -- & 1 & 2 & 3 & 4 & 5 & 1 & 2 & 3 & 4 & 5 & -- & -- \\
\hline$G_{f}(\mathrm{~N} / \mathrm{mm})$ & -- & 0.3 & 0.9 & 0.9 & 0.9 & 1.5 & 0.3 & 0.9 & 0.9 & 0.9 & 1.5 & -- & -- \\
\hline$\tau_{y}(\mathrm{MPa})$ & -- & 3.61 & 1.57 & 6.26 & 25.1 & 8.08 & 3.61 & 1.57 & 6.26 & 25.1 & 8.08 & -- & -- \\
\hline $\begin{array}{c}\text { Experimental shear } \\
\text { strength } V_{\exp }(\mathrm{kN})\end{array}$ & 181 & \multicolumn{7}{|c|}{285} & \multicolumn{7}{|c|}{236} & & 184 & 166 \\
\hline $\begin{array}{c}\text { Analyzed shear strength } \\
V_{\text {cal }}(\mathrm{kN})\end{array}$ & 171 & 250 & 243 & 241 & 247 & 241 & 216 & 211 & 216 & 222 & 216 & 168 & 177 \\
\hline$V_{\text {cal }} / V_{\exp }$ & 0.95 & 0.88 & 0.85 & 0.85 & 0.87 & 0.85 & 0.92 & 0.89 & 0.91 & 0.94 & 0.92 & 0.91 & 1.06 \\
\hline $\begin{array}{c}\text { Analyzed sheet strain at } \\
V_{\max }\left(\mathrm{x} 10^{-3}\right)\end{array}$ & --- & 2.10 & 2.24 & 1.44 & 1.68 & 1.36 & 0.49 & 0.70 & 0.86 & 0.69 & 0.68 & 1.89 & 0.94 \\
\hline
\end{tabular}

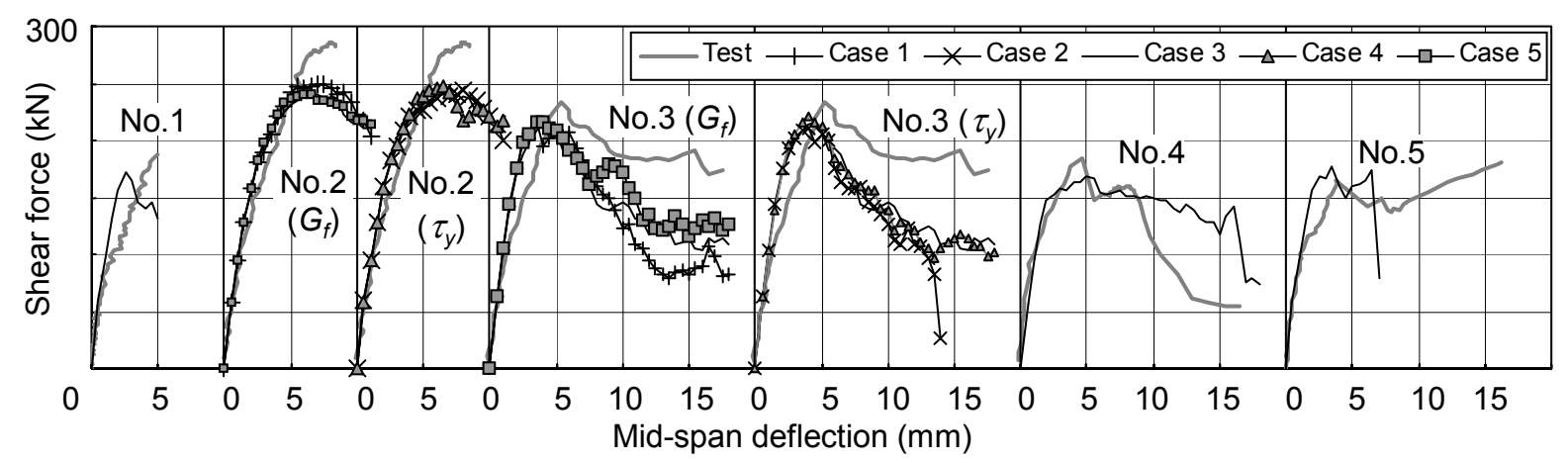

Fig.5 Shear force-deflection relationships of Ishizaki's specimens.

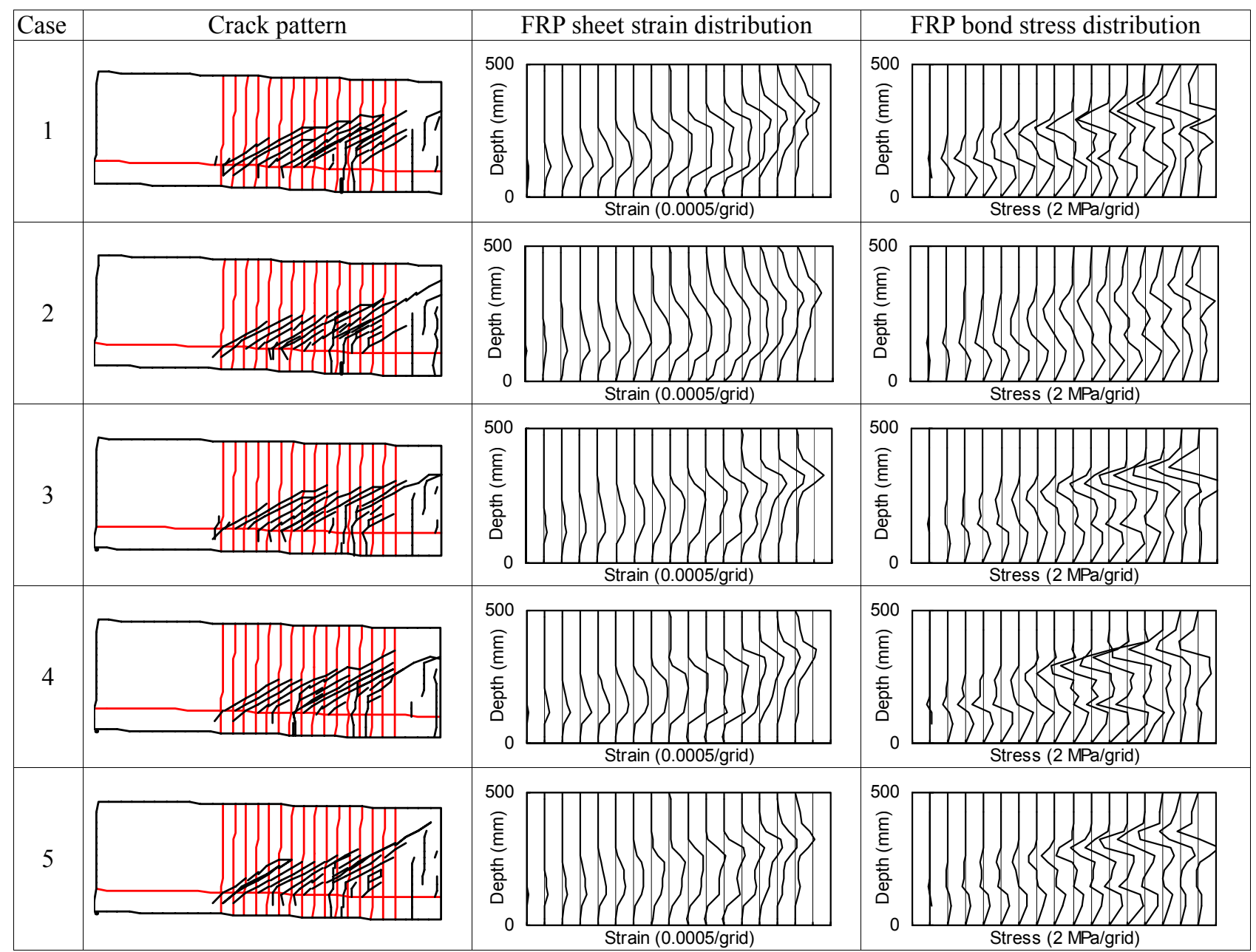

Fig.6 Analyzed crack patters, sheet strains and bond stresses of Specimen No.2 at maximum shear force. 
represent $20 \mathrm{~mm}$-thick finishing mortars under FRP sheets. Table 6 summarizes the analysis results. The shear force reached maximum at a drift angle around $1.5 \%$ and then began to decrease because of compressive fracture of concrete (Fig. 7).

Five cases of calculations for Specimens S-RC-B and S-M12-B also resulted in slight variation in ductility as well as shear strength. The calculated average FRP strain (at drift angle of $1.5 \%$ ) ranged from $3.12 \times 10^{-3}$ to $4.36 \times 10^{-3}$. Increasing $G_{f}$ of Specimens S-RC-B and $\mathrm{S}-\mathrm{M} 12-\mathrm{B}$ reduced the sheet strains. Figure 8 presents crack patterns, FRP strains, and bond stresses of Specimen S-M12-B at drift angle of $1.5 \%$.

\section{Sheet strains in beams with no stirrup}

Figure 9 compares between analysis and test results of the sheet strains of Ishizaki's specimens with respect to shear force. The presented strains are average of four strains measured along dominant shear crack. The sheet strains firstly remain under 0.0005 and begin to increase after shear cracking at an approximately $150 \mathrm{kN}$ shear force. The sheet strain of Specimen No.2, where carbon fiber sheets were bonded, increased up to 0.005 while that of Specimen No.3 with aramid fiber remained under 0.001 until the shear force reached the maximum. Influence of the bond characteristics on the sheet strain is not significant in both Specimens No.2 and No.3 at pre-peak stage. On the other hand, comparison between specimens with bonded and unbonded sheets shows remarkable difference at post-cracked stage. The shear forces increased after shear cracking in specimens with bonded sheets (No.2 and No.3) while the shear force of those with unbonded sheets remained on lower levels.

Table 6 Analysis results (Fukuyama 1998).

\begin{tabular}{|c|c|c|c|c|c|c|c|c|c|c|c|c|c|}
\hline Specimen & S-RC-0 & \multicolumn{5}{|c|}{ S-RC-B } & S-RC-N & \multicolumn{5}{|c|}{ S-M12-B } & S-M12-BP \\
\hline Case & -- & 1 & 2 & 3 & 4 & 5 & -- & 1 & 2 & 3 & 4 & 5 & -- \\
\hline$G_{f}(\mathrm{~N} / \mathrm{mm})$ & -- & 0.3 & 0.9 & 0.9 & 0.9 & 1.5 & -- & 0.3 & 0.9 & 0.9 & 0.9 & 1.5 & -- \\
\hline$\tau_{y}(\mathrm{MPa})$ & -- & 3.61 & 1.57 & 6.26 & 25.1 & 8.08 & -- & 3.61 & 1.57 & 6.26 & 25.1 & 8.08 & -- \\
\hline $\begin{array}{c}\text { Experimental } \\
\text { shear strength } \\
V_{\exp }(\mathrm{kN})\end{array}$ & 236 & \multicolumn{5}{|c|}{288} & 270 & \multicolumn{5}{|c|}{338} & 340 \\
\hline $\begin{array}{l}\text { Analyzed shear } \\
\text { strength } V_{c a l} \\
(\mathrm{kN})\end{array}$ & 200 & 287 & 271 & 267 & 283 & 280 & 307 & 340 & 332 & 333 & 339 & 336 & 328 \\
\hline$V_{c a l} / V_{\text {exp }}$ & 0.85 & 1.00 & 0.94 & 0.93 & 0.98 & 0.97 & 1.14 & 1.01 & 0.98 & 0.99 & 1.00 & 0.99 & 0.96 \\
\hline $\begin{array}{c}\text { Analyzed sheet } \\
\text { strain at } R= \\
1.5 \%\left(\times 10^{-3}\right)\end{array}$ & --- & 4.29 & 3.64 & 3.70 & 3.67 & 3.25 & 3.66 & 4.36 & 3.84 & 3.76 & 3.82 & 3.35 & 3.12 \\
\hline
\end{tabular}

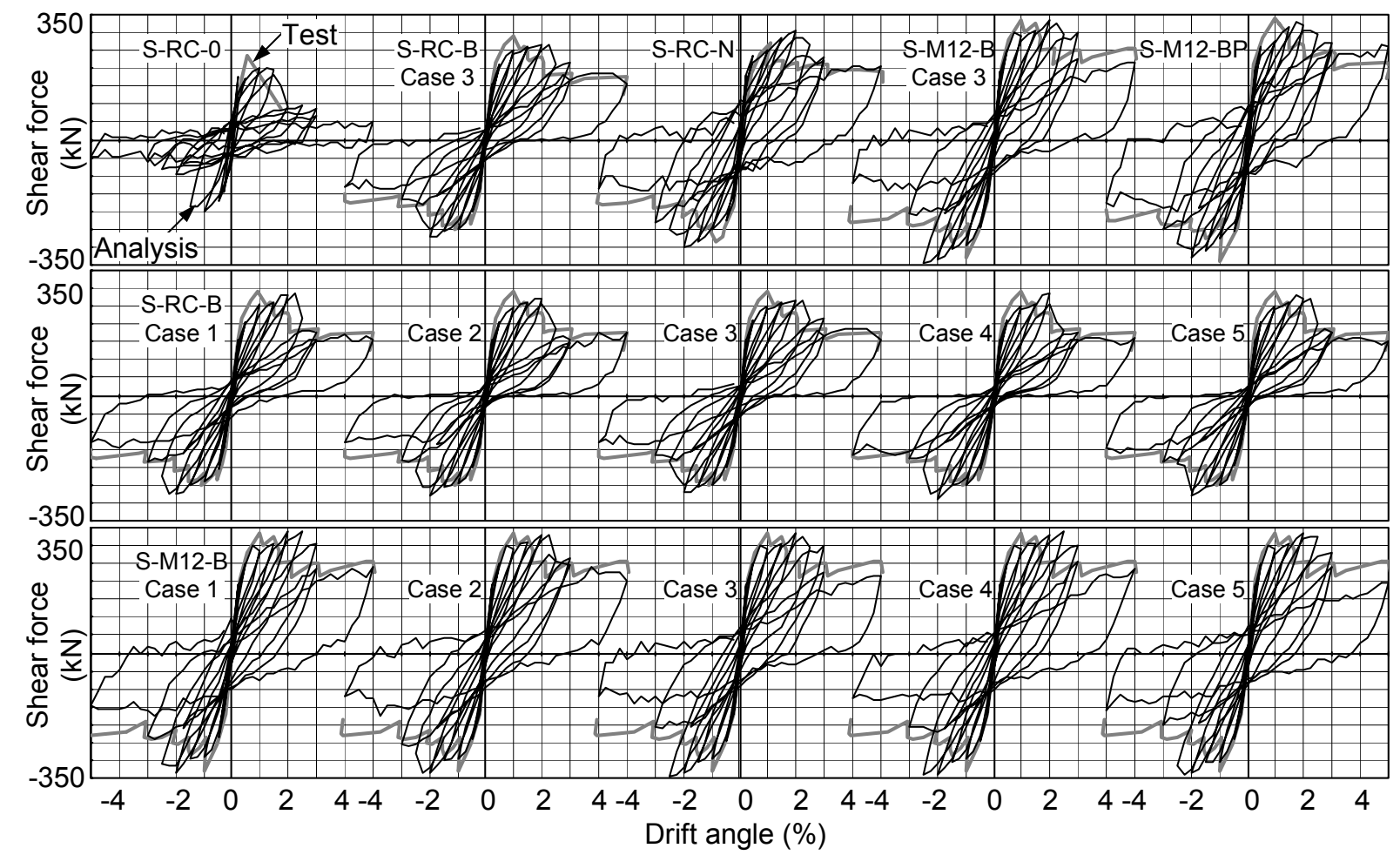

Fig.7 Shear force-drift angle relationships of Fukuyama's specimens. 


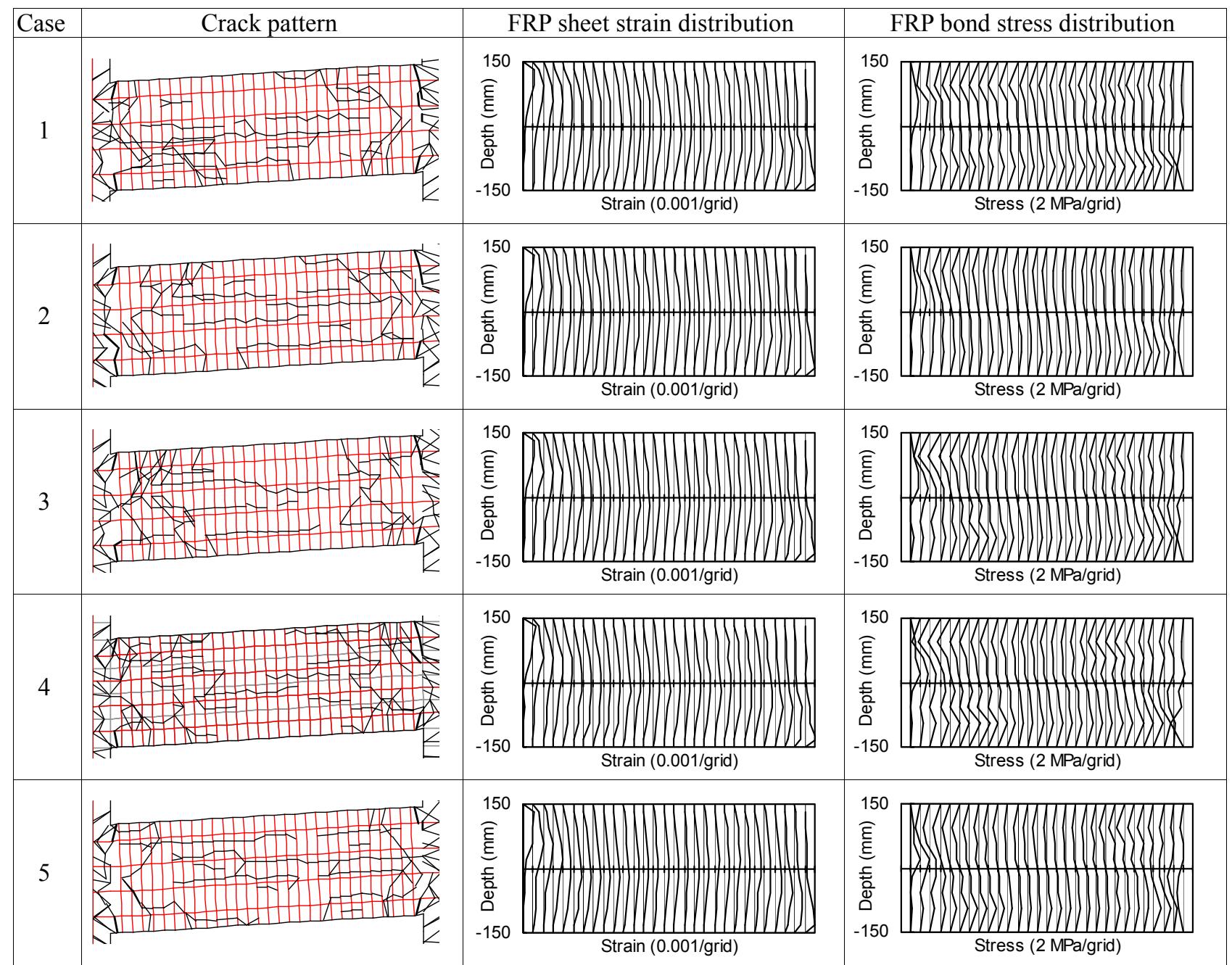

Fig.8 Analyzed crack patterns, sheet strains and bond stresses of Specimen S-M12-B at drift angle of $1.5 \%$.

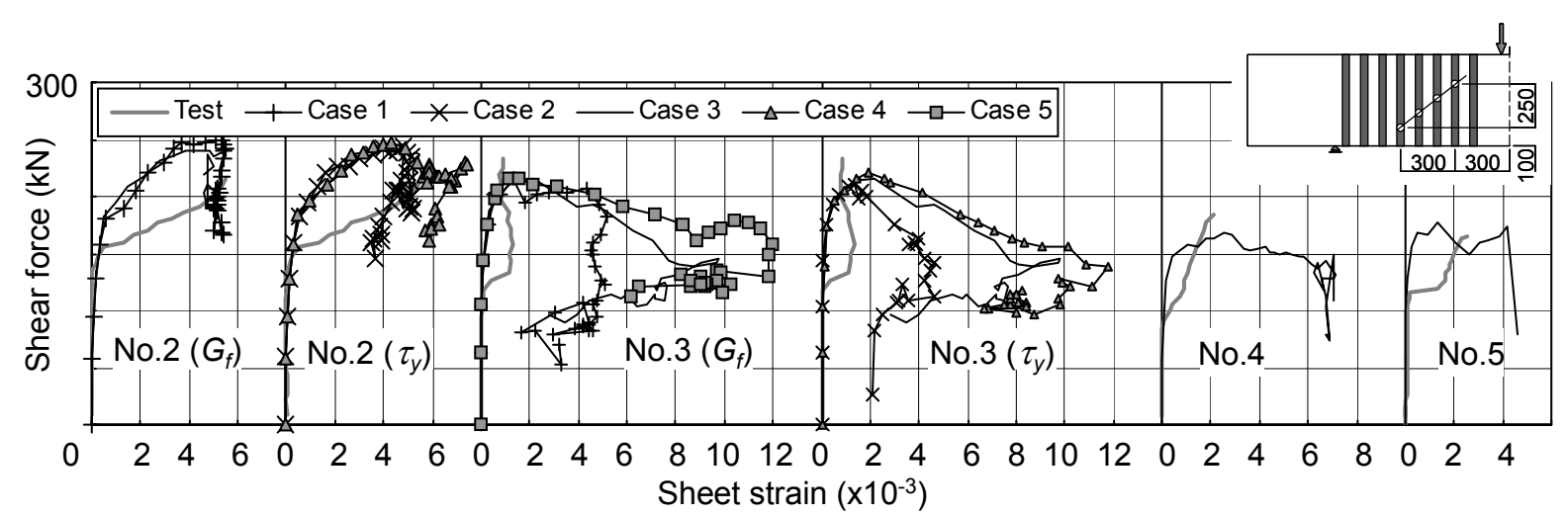

Fig. 9 Shear force-sheet strain relationships of Ishizaki's specimens.

The above observation indicates importance of the bonding of FRP sheets. Nevertheless, the strengthening effectiveness is sufficiently achieved even with very low interfacial fracture energy $G_{f}$ of $0.3 \mathrm{~N} / \mathrm{mm}$.

\section{Sheet strains in ductile columns}

Figure 10 compares analysis and test results of the sheet strains of Specimen S-M12-B with respect to drift angle.
The presented strain is the one measured at mid-depth at mid-span. In the test, the strains reached to 0.008 at a drift angle of $1.5 \%$, where maximum shear force of the column was observed. Then the strain continued to increase with a smaller gradient and reached around 0.01 at a drift angle of $5 \%$. The analysis results generally agreed with the test although discrepancy was found at drift angle of $5 \%$. 


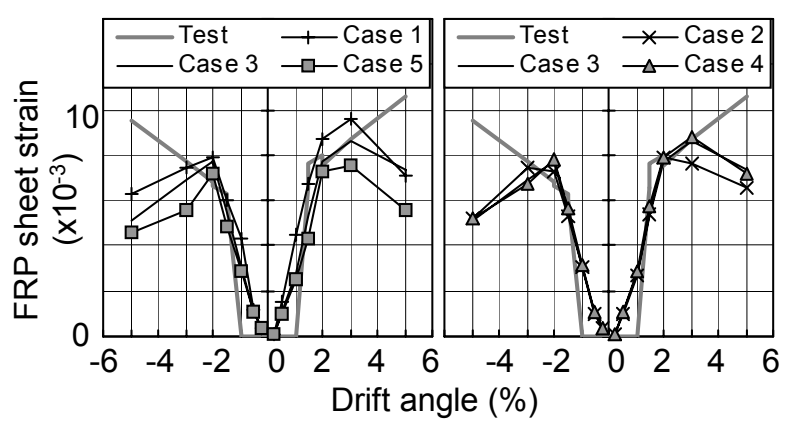

Fig.10 Sheet strain-drift angle relationships of Specimen S-M12-B.

\section{Crack width}

Ishizaki et al. measured crack width of the dominant shear crack in Specimens No.2, 3, 4, and 5. Figure 11 compares between analysis and test results of crack widths at a location $400 \mathrm{~mm}$ distanced from the loading point. The crack width of Specimen No.2 remained under $0.2 \mathrm{~mm}$ while larger widths were observed after shear cracking in other specimens. As mentioned in the previous section, a lightly shear-reinforced member collapses when the dominant shear crack opens by a certain width.

Test result of Specimen No.2 indicated that the bonded carbon fiber sheets were effective to limit the crack width opening, whereas aramid fiber sheets or unbonded sheets were less effective. In the analyses, the crack width of Specimen No.2 at maximum shear force was reduced when the fracture energy $G_{f}$ of $0.3 \mathrm{~N} / \mathrm{mm}$ (Case 1) was adopted. The bond stress with a large $\tau_{y}$ (Case 4) also reduced the width. However, the reduction in the crack width did not resulted in remarkable increase of the shear strength of Specimen No.2. These observations indicate that strengthening of a member without shear reinforcing steel requires usage of high-stiffness sheet and bonding of the sheet.

\section{Influences of interfacial fracture energy and maximum bond stress}

Figure 12 summarizes influences of the fracture energy $G_{f}$ and the maximum bond stress $\tau_{y}$ on the calculated shear strength, average sheet stress $\left(\rho_{F} f_{F}\right)$, and average crack width. The maximum bond stress $\tau_{y}$ in Fig. 12 is normalized by dividing by $6.6 \sqrt{G_{f}}$, where $G_{f}=0.9$ $\mathrm{N} / \mathrm{mm}$. Four lines indicate results of Specimens No.2, No.3, S-RC-B and S-M12-B. As the fracture energy $G_{f}$ increases, the sheet stress $\rho_{F} f_{F}$ decreases while the crack width increases, although Specimen No.3 presents exceptional tendencies. Note that the crack widths of Specimens No.2 and No.3 represent widths of the dominant shear cracks, while those of Specimens S-RC-B and S-M12-B average widths of all cracks in the column. On the other hand, influence of the maximum bond stress $\tau_{y}$ on the $\rho_{F} f_{F}$ and the crack width is insignificant. Furthermore, variations of the $G_{f}$ and the $\tau_{y}$ resulted in slight changes of the shear strengths.

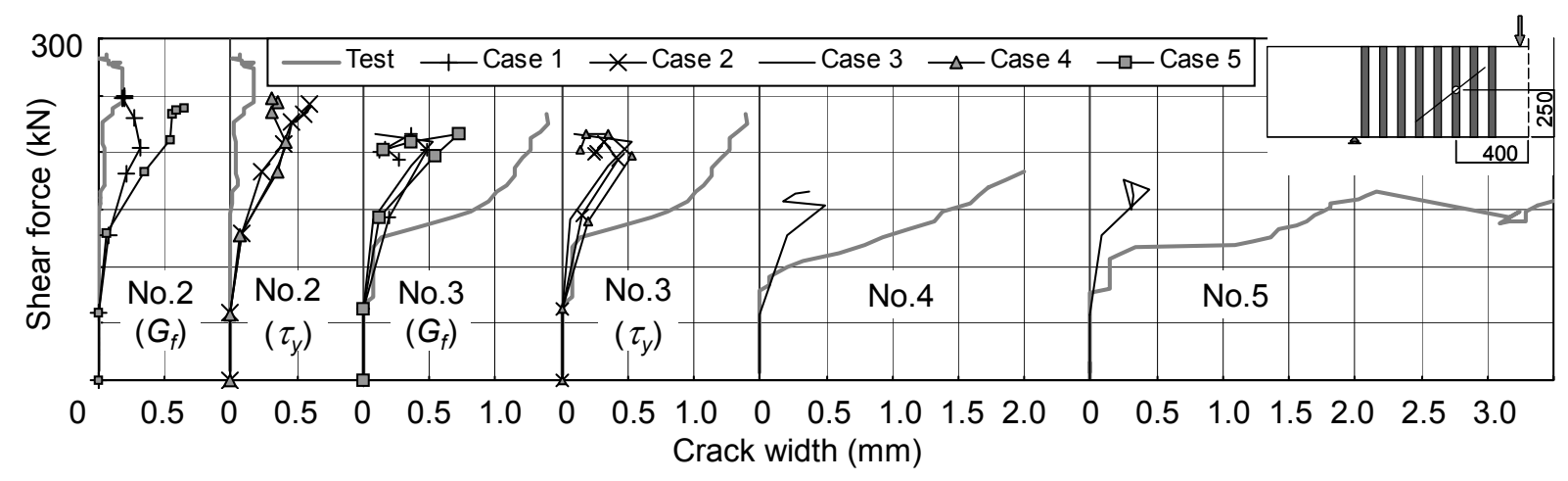

Fig.11 Shear force-crack width relationships of Ishizaki's specimens.
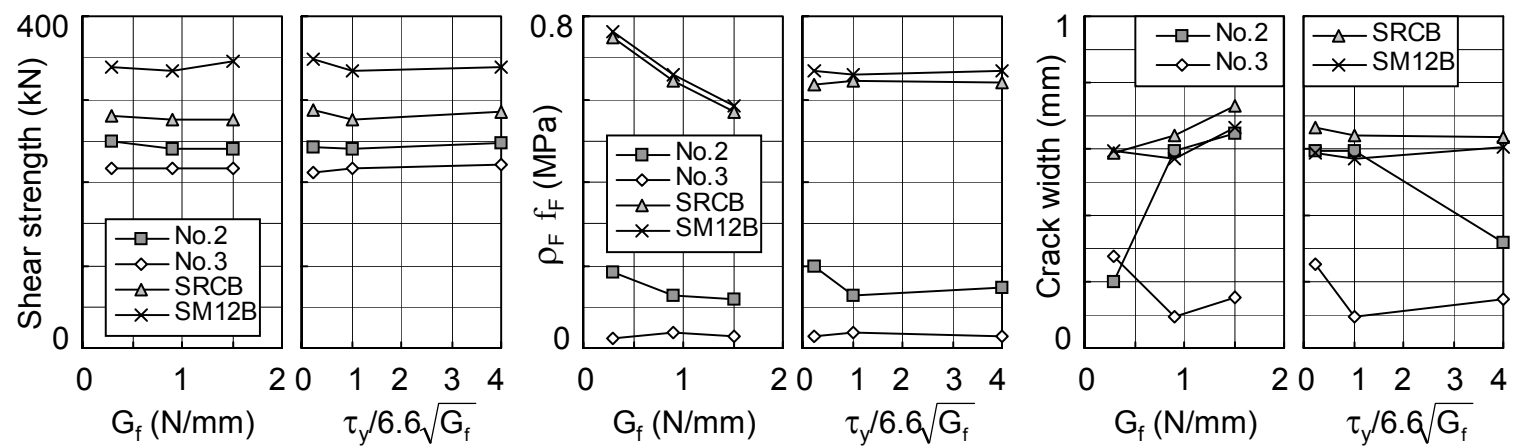

Fig.12 Influences of bond characteristics on calculated shear strength, sheet stress, and crack width. 
These results indicate that improvement of the bond characteristics cannot increase the shear strength of retrofitted member although the sheet stress and the crack width can be controlled by the $G_{f}$ and the $\tau_{y}$.

\section{Conclusions}

A concrete member with no shear-reinforcing steel needs bonding of the FRP sheets to achieve sufficient strengthening effectiveness, although flexural ductility can be improved by confinement with unbonded sheets. The interfacial fracture energy $G_{f}$ and the maximum bond stress $\tau_{y}$ influences to response of a strengthened $\mathrm{RC}$ member to a certain extent. The analysis results indicated that distributions of cracks, sheet strains, and bond stresses changed corresponding to the variation of $G_{f}$ and $\tau_{y}$.

The authors state that improvement of the bond capacity is probably worthwhile for strengthening of a low-reinforced member with high-stiffness FRP sheet (JCI 2003). However, the calculations with improved analytical models indicated that the $G_{f}$ and the $\tau_{y}$ are not influential factor for the strengthening effectiveness. Even low interfacial fracture energy $G_{f}$ of $0.3 \mathrm{~N} / \mathrm{mm}$ between the sheet and concrete provides sufficient enhancement in shear strength as long as the sheets are wrapped around a RC member.

\section{Acknowledgements}

The authors are grateful to Professor T. Ueda of Hokkaido University, Dr. Kamiharako of Hirosaki University and Dr. Kanakubo of Tsukuba University for their kind supports.

\section{References}

Asakura, A. Okamoto, T., Tanigaki, S. and Oda, M. (1994). "Shear strengthening of existing reinforced concrete column by winding with high strength fiber." Proc. JCI, 16(1), 1061-1066. (in Japanese)

Fukuyama, H., et al. (1998). "Influences of RC column retrofitted with continuous fiber sheet." Proc. Symposium on Continuous Fiber Reinforced Concrete, JCI, ISBN 4-931451-03-9 C 3050, 133-149. (in Japanese)

Fujii, S., Morita, S., Goto, S., Konishi, T. and Yoshimi, K. (1981). "Evaluation of bond splitting strength." Annu. Rep. Architectural Institute of Japan, Kinki Branch, 197-204. (in Japanese)

He, X. G. and Kwan, A. K. H. (2001). "Modeling dowel action of reinforcement bars for finite element analysis of concrete structures." Computers and Structures, 79(6), 595-604.

Ishizaki, K., Maruyama, K., Shimomura, T. and Takada, K. (1997). "Size effect of RC member retrofitted with continuous fiber sheet." Proc. JCI, 19(2), 201-206. (in Japanese)
JCI (1998). "Technical Report on Continuous Fiber Reinforced Concrete." JCI TC952 on Continuous Fiber Reinforced Concrete, 116-124.

JCI (2003). "Technical Report on Retrofitting Technology for Concrete Structures." Technical Committee on Retrofitting Technology for Concrete Structures, 79-97.

Kupfer, H., Hilsdorf, H. K. and Rusch, H. (1969). "Behavior of concrete under biaxial stress." ACI J., 87(2), 656-666.

Palermo, D. and Vecchio, F. J. (2003). "Compression field modeling of reinforced concrete subjected to reversed loading: Formulation." ACI Struct. J., 100(5), 616-625.

Park, R., Priestly, M. J. and Gill, W. D. (1982). "Ductility of square-confined concrete columns." $J$. Struct. Div., ASCE, 108(4), 929-950.

Richart, F. E., Brandtzaeg, A. and Brown, R. L. (1928). "A Study of the Failure of Concrete under Combined Compressive Stresses." Bulletin No.185, University of Illinois Engineering Experimental Station, Urbana, Illinois, 104.

Sato, Y., Katsumata, H. and Hagio, H. (1999) "Shear strengths of RC beams retrofitted with continuous fiber sheet." J. Structural and Construction Engrg., Architectural Institute of Japan, 526, 125-132. (in Japanese)

Sato, Y. and Vecchio, F. J. (2003a). "Tension stiffening and crack formation in reinforced concrete members with fiber-reinforced polymer sheets." ASCE J. Struct. Engrg., 129(6), 717-724.

Sato, Y., Ko, H., Akada, T. and Sakai, Y. (2003b). "Buckling of longitudinal bars of RC columns strengthened with continuous fiber sheet." Proc. JCI, 2036 (in Japanese).

Sato, Y., Nagatomo, K. and Nakamura, Y. (2003c). "Bond-strengthening hooks for RC members with $1300 \mathrm{MPa}$-class shear-reinforcing spirals." J. Asian Architecture and Building Engrg., 2(2), 7-14.

Seckin, M. (1981). "Hysteretic Behaviour of Cast-in-Place Exterior Beam-Column-Slab Subassemblies." Ph. D. Thesis, Department of Civil Engineering, University of Toronto, 266 .

Vecchio, F. J. and Collins, M. P. (1986). "The modified compression-field theory for reinforced concrete elements subjected to shear." ACI Struct. J., 83(2), 219-231.

Vecchio, F. J. (1992). "Finite element modeling of concrete expansion and confinement." ASCE J. Struct. Engrg., 118(9), 2390-2406.

Vecchio, F. J. (2000). "Disturbed stress field model for reinforced concrete: Formulation." ASCE J. Struct. Engrg., 126(9), 1070-1077.

Walraven, J. C. (1981). "Fundamental analysis of aggregate interlock." ASCE J. Structural Div., 107(11), 2245-227. 